\title{
Pharmacodynamics and Pharmacokinetics Evaluation of Ranitidine Microemulsion on Experimental Animals
}

\author{
Sajal Kumar Jha, ${ }^{1}$ Roopa Karki, ${ }^{2}$ Venkatesh Dinnekere Puttegowda, ${ }^{2}$ and Amitava Ghosh ${ }^{1}$ \\ ${ }^{1}$ Department of Pharmaceutics, Bengal College of Pharmaceutical Sciences \& Research, BRB Sarani, Bidhannagar, \\ Durgapur, West Bengal 713212, India \\ ${ }^{2}$ Department of Industrial Pharmacy, Acharya \& BM Reddy College of Pharmacy, Soldevanahalli, Bangalore, \\ Karnataka 560090, India \\ Correspondence should be addressed to Sajal Kumar Jha; sajal.kumar.jha@gmail.com
}

Received 18 July 2014; Revised 29 August 2014; Accepted 2 October 2014; Published 20 October 2014

Academic Editor: Maria Cristina Bonferoni

Copyright (C) 2014 Sajal Kumar Jha et al. This is an open access article distributed under the Creative Commons Attribution License, which permits unrestricted use, distribution, and reproduction in any medium, provided the original work is properly cited.

Ranitidine microemulsion was investigated for its pharmacodynamic and pharmacokinetic evaluation to find out the suitability of microemulsion as a potential drug delivery system in the treatment of ulcer. The bioavailability of ranitidine after oral administration is about $50 \%$ and is absorbed via the small intestine; this may be due to low intestinal permeability. Hence the aim of present investigation was to maximize the therapeutic efficacy of ranitidine by developing microemulsion to increase the intestinal permeability as well as bioavailability. A ground nut oil based microemulsion formulation with Tween-80 as surfactant and PEG-400 as cosurfactant was developed for oral delivery of ranitidine and characterized for physicochemical parameters. In pharmacodynamic studies, significant $(P<0.05)$ variation in parameters estimated was found between the treated and control groups. Ranitidine microemulsion exhibited higher absorption and $\mathrm{C}_{\max }(863.20 \mathrm{ng} \cdot \mathrm{h} / \mathrm{mL})$ than the standard $(442.20 \mathrm{ng} / \mathrm{mL})$. It was found that $\mathrm{AUC}_{0-24} \mathrm{hr}$ obtained from the optimized ranitidine test formulation $(5426.5 \mathrm{ng} \cdot \mathrm{h} / \mathrm{mL})$ was significantly higher than the standard ranitidine $(3920.4 \mathrm{ng} \cdot \mathrm{h} / \mathrm{mL})$. The bioavailability of optimized formulation was about 1.4-fold higher than that of standard drug. This enhanced bioavailability of ranitidine microemulsion may be used as an effective and alternative drug delivery system for the antiulcer therapy.

\section{Introduction}

Gastric ulcer is said to occur due to an imbalance between luminal acid synthesis and mucosal defense. Acid and pepsin components constitute the aggressive factors, and the mucous layer of mucin-bicarbonate secretion, prostaglandins, and other healing factors constitute the defensive factors [1]. The mucosal defense against these aggressive factors includes the function of the mucus-bicarbonate barrier, surface active phospholipids, prostaglandin, mucosal blood flow, cell renewal and migration, antioxidative enzymes, and some growth factors.

Even though wide range of drugs available for the treatment of ulcer may do not fulfill the requirements and have many side effects such as arrhythmias, impotence and hemopoietic changes are noted. $\mathrm{H}_{2}$ antagonists, unlike anticholinergics, do not delay gastric emptying time which may reflexly stimulate gastric secretion because of food remaining in the stomach for long time. Also it does not cause abdominal colic and diarrhoea caused by proton pump inhibitors. In recent years large advance in chemical and pharmacological studies has contributed to the knowledge about new therapeutically active compounds and control drug delivery systems for peptic ulcer. Out of the available category of drugs for the treatment of ulcer, $\mathrm{H}_{2}$ antagonist's class of drugs like famotidine and ranitidine is considered to be the safest drugs available [2].

Ranitidine ( $N-\{2-[(\{5-[($ dimethylamino)methyl $]-2-f u-$ ranyl $\}$ methyl ) thio ] ethyl $\}$ - $N$-methyl-2-nitro-1,1-ethylenediamine) is a selective and competitive histamine $\mathrm{H}_{2}$-receptor 
antagonist with an extensive clinical history in the treatment of gastric and duodenal ulcers, gastroesophageal reflux disease (GERD), and Zollinger-Ellison syndrome.

The bioavailability of ranitidine after oral administration is about $50 \%$ and is absorbed via the small intestine [3]; this may be due to low intestinal permeability. The extent of drug release is also shorter which requires repeated dose administration that leads to increased adverse effect. In order to overcome these problems an attempt was made to develop microemulsion drug delivery system for ranitidine.

\section{Materials and Methods}

2.1. Chemicals. Ranitidine USP was obtained from SMS Pharmaceuticals Pvt. Ltd. (Hyderabad, India) as free gift sample. PEG-400 was purchased from BD Pharmaceuticals Ltd. (Kolkata, India), and Tween-80 was purchased from Merck Specialties Pvt. Ltd. (Mumbai, India). All other chemicals used in this study were obtained commercially and were of analytical (AR) grade.

2.2. Preparation and Characterization of Formulations. A ground nut oil based microemulsion formulation was developed with Tween-80 as surfactant and PEG-400 as cosurfactant. Microemulsion was prepared by using phase titration method keeping constant weight ratio of surfactant/cosurfactant (i.e., $K_{m}=2: 1$ ). Drug loaded microemulsion system (R-1) was prepared by dissolving ranitidine $(150 \mathrm{mg} / \mathrm{mL})$ in water by gentle heating and drug solution $(1.4 \mathrm{~mL})$ was precisely added drop by drop to the oily phases with magnetic stirring at ambient temperature. After the resulting systems were equilibrated with gentle magnetic stirring, they were ultrasonicated.

Droplet size distribution of optimized microemulsion was determined by photon correlation spectroscopy, using a Delsa Nano-C (Beckman Coulter Instruments) based on light scattering phenomenon, which analyzes the fluctuations in light scattering. Light scattering was monitored at $25^{\circ} \mathrm{C}$ at a scattering angle of $90^{\circ}$. Electrophoretic mobility $(\mu \mathrm{m} / \mathrm{s})$ was measured using small volume disposable zeta cell and converted to zeta potential by in-built software using HelmholtzSmoluchowski equation. The percentage transmittance of samples was measured at 650 and $400 \mathrm{~nm}$ with distilled water taken as blank and three replicates were performed for each sample. The $\mathrm{pH}$ values of the microemulsion were measured by a $\mathrm{pH}$ meter (Digital Systronics, Mumbai, India) at ambient temperature with glass electrode. The viscosity measurement of the prepared microemulsion was performed using Brookfield's viscometer (Brookfield LVDV-II + pro viscometer) at single mode using spindle \# CPE41 at $32 \pm$ $0.5^{\circ} \mathrm{C}$. All aspects of testing were controlled using Rheocalc Software.

2.3. Thermodynamic Stability Studies. To overcome the problem of metastable formulation, thermodynamic stability tests were performed. Selected formulations were centrifuged at $3000 \mathrm{rpm}$ for $30 \mathrm{~min}$. Those formulations that did not show any phase separation were taken for the heating and cooling cycle at temperature of $2^{\circ} \mathrm{C}, 25^{\circ} \mathrm{C}$, and $50^{\circ} \mathrm{C}$ for 3 months as well as for 6 months. After 6 months of storage, the formulation (R-1) was subjected to test for phase separation, percentage transmittance, \% cumulative drug release, and drug precipitation.

2.4. Animals. Swiss albino rats weighing 150-200 g of either sex were used for this experiment and were selected at random from animal house of the Pinnacle Biomedical Research Institute (PBRI), Bhopal. Institutional animal ethics committee approved the experimental protocol; animals were maintained under standard conditions in an animal house approved by committee for the purpose of control and supervision on experiments on animals (CPCSEA). All animal experiments were approved by Institutional Animal Ethics Committee (IAEC) of PBRI (Regd. no. 1283/C/09/CPCSEA) with protocol approval reference number PBRI/IAEC/11/PN144. The animals were housed in polypropylene cages and maintained at $24^{\circ} \mathrm{C} \pm 2^{\circ} \mathrm{C}$ under $12 \mathrm{~h}$ light/dark cycle, were feed ad libitum with standard pellet diet (Golden Feed, New Delhi), and had free access to water.

2.5. Ethanol-Induced Ulcer Model. Swiss Albino rats of either sex weighing 150-200 g were divided into three groups with each group consisting of six animals. The animals were fasted for $24 \mathrm{~h}$ with free access water. Group I served as normal control, in which normal saline was administered orally; Group II received ranitidine $20 \mathrm{mg} / \mathrm{kg}$ orally and it was considered as standard; Group III served as ranitidine formulation group and the dose equivalent to ranitidine $20 \mathrm{mg} / \mathrm{kg}$ was administered. Animals were given test drugs or standard drug. One hour later, $1 \mathrm{~mL} / 200 \mathrm{~g}$ of $99.80 \%$ alcohol was administered orally to each animal. The animals were anaesthetized $1 \mathrm{~h}$ later with ether, the stomach was incised along the greater curvature, and ulceration was scored. The number of ulcers and the length of each ulcer were measured. Ulcer index was calculated using severity scores and average number of ulcers per animal [4].

2.6. Statistical Analysis. Data are presented as mean \pm SEM (standard error of the mean) and $n$ represents the number of rats used for a particular experiment. Comparisons were made between treated and control groups using one-way analysis of variance (ANOVA) followed by Dunnett's test and significance of difference was accepted at $P<0.05$.

2.7. Pharmacokinetics Study. All animal procedures were performed in accordance with protocols reviewed and approved by the Committee for the Purpose of Control and Supervision on Experimental Animals (CPCSEA).

The pharmacokinetic study of the microemulsion containing ranitidine was conducted in New Zealand rabbits weighing $2.5-3.0 \mathrm{Kg}$. The rabbits have been chosen as the model for study because there have been many bioavailability studies done using this animal model. The rabbits were housed individually with free access to food and water. A $12 \mathrm{~h}$ light/ $12 \mathrm{~h}$ dark cycle was held to keep a normal circadian rhythm in the animals. 
Six rabbits were divided into three groups and fasted for 24 hours. Control batch was fed with normal saline, test batch was fed with $20 \mathrm{mg} / \mathrm{kg}$ ranitidine (pure drug), and the test batch was given the formulation equivalent to $20 \mathrm{mg} / \mathrm{kg}$ of drug. Water was given ad libitum during fasting and throughout the experiment. The blood samples (approximately $300-400 \mu \mathrm{L}$ ) were collected from the marginal ear vein of the rabbits using heparinized needle (20-24 in size) at predetermined time intervals, specifically at $0.5,2,6,8,10$, 12 , and 24 hours after oral administration.

The heparinized blood samples were immediately collected in centrifugation tubes $(5 \mathrm{~mL})$ and centrifuged at $20000 \mathrm{rpm}$ at $0^{\circ} \mathrm{C}$ for 15 minutes. Supernatant layer of plasma was separated into another centrifugation tube and stored at $-20^{\circ} \mathrm{C}$ until analysis [5].

2.8. LC-MS/MS Instrument. The 1200 Series HPLC system (Agilent Technologies, Waldbronn, Germany) was used. Mass spectrometric detection was performed on an API 3200 triple-quadrupole instrument (Applied Biosystems/MDS SCIEX, Toronto, Canada). Data processing was performed on Analyst 1.4.2 software package (SCIEX) [6].

2.9. Chromatographic Method Conditions. Agilent Zorbax SB-CN (50 mm $\times 2.1 \mathrm{~mm}$ I.D., 5 microns) was selected as the analytical column. The mobile phase was composed of methanol: $20 \mathrm{mM}$ ammonium acetate $(55: 45, \mathrm{v} / \mathrm{v})$. The flow rate of the mobile phase was set at $0.6 \mathrm{~mL} / \mathrm{min}$ and the injection volume was $10 \mu \mathrm{L}$. The column temperature was set at $20^{\circ} \mathrm{C}$. The retention times of ranitidine were found to be approximately $0.91 \pm 0.12 \mathrm{~min}$.

2.10. Sample Preparation/Extraction Procedure. An aliquot $50 \mu \mathrm{L}$ plasma was used for analysis. All samples and standards were made slightly acidic by addition of $10 \mu \mathrm{L}$ of $0.1 \mathrm{M}$ aqueous ammonium acetate $(\mathrm{pH} 6)$ and were extracted into $3 \mathrm{~mL}$ of ethyl acetate. The extraction tubes were shaken at high speed for $5 \mathrm{~min}$ followed by centrifugation at $6000 \mathrm{rpm}$ for $5 \mathrm{~min}$. The organic phase was transferred to clean glass tubes and evaporated to dryness in a $45^{\circ} \mathrm{C}$ water bath under a nitrogen stream. The samples were reconstituted within $200 \mu \mathrm{L}$ of mobile phase and vortexed for $30 \mathrm{sec}$. After transfer into glass inserts of autosampler vials, an aliquot of $10 \mu \mathrm{L}$ of each sample was injected onto the LC-MS/MS system [7].

2.11. Pharmacokinetic Data Analysis. After oral administration of the microemulsion and standard drug, plasma samples were analyzed by LC-MS/MS for their ranitidine content. A curve of cumulative drug absorbed versus time curved from 0 to 24 hours was plotted to calculate the area under curve (AUC). Other pharmacokinetic parameters, that is, peak plasma level $\left(C_{\max }\right)$ and time to reach peak plasma level $\left(T_{\max }\right)$, were obtained after analysis of the individual time-plasma concentrations.
TABLE 1: Composition of ranitidine microemulsion.

\begin{tabular}{lc}
\hline Ingredients (by wt) & Ranitidine microemulsion (R-1) \\
\hline Ranitidine (mg/mL) & 150 \\
Ground nut oil & 6.67 \\
Smix (Tween-80 : PEG 400) & 60.00 \\
Water & 33.33 \\
\hline
\end{tabular}

\section{Results and Discussions}

3.1. Physicochemical Characterization of Formulation. Microemulsion formulations (nine batches) containing ground nut oil as an oil phase were prepared at Tween80 and PEG 400 fixed Smix ratios of 2:1 (Table 1). All formulations were prepared and characterized for the various physicochemical parameters (Table 2). The narrow globule size range of $16.2 \pm 1 \mathrm{~nm}$ and polydispersity index $0.135 \pm 0.017$ for R-1 indicated that the microemulsion approached a monodispersed stable system and could deliver the drug effectively owing to larger surface area. The presence of zeta potential to the tune of $-3.02 \pm 0.18 \mathrm{mV}$ on the globules of R-1 conferred physical stability to the system. The microemulsions were expected to have good physical stability (phase separation) as zeta potential is less than -30 to $-40 \mathrm{mV}$ [8-10]. A percentage transmittance of $98.2 \%$ for R-1 indicated clear dispersion. The $\mathrm{pH}$ of the optimized ranitidine microemulsion was found to be $7.32 \pm 1.12$, approximating the normal blood $\mathrm{pH}$ (7.4).

It was observed that the viscosity of the microemulsion formulation generally was very low $(65.38 \pm 0.982 \mathrm{cp})$. This was expected, because one of the characteristics of microemulsion formulations is of lower viscosity [11-13]. Low viscosity value of R-1 ensures easy handling, packing, and hassle-free oral administration of formulations.

In stability studies, formulation R-1 was found to be stable for 3 months at intermediate and accelerated conditions and 6 months at long-term conditions. There was no significant change in \% transmittance, \% cumulative drug release of the resultant microemulsions. Furthermore, the formulations were found to show no phase separation, drug precipitation, thus substantiating the stability of formulations for 6 months (Table 3).

3.2. Antiulcer Activity. Ethanol is considered a risk factor for developing gastric ulcers. It readily penetrates the gastric mucosa due to its ability to solubilize the protective mucous and expose the mucosa to the proteolytic and hydrolytic actions of hydrochloric acid and pepsin, causing damage to the membrane [14]. The ulcer index in ethanol-induced control animals was UI $=13 \pm 1.0$. The reduction in ulcer index was observed in standard (UI $=5 \pm 0.63$ ) and in test formulation ( $\mathrm{UI}=2.5 \pm 0.92)$ was significant $(P<0.05)$ when compared to control. Similarly, ranitidine formulation has significantly reduced mucosal damage $(80.77 \%)$ as compared to standard ranitidine $(61.54 \%)$ induced by ethanol, which suggests that ranitidine formulation strengthens and protects the gastric mucosal barrier (Table 4, Figures 1 and 2). 
TABLE 2: Characterization parameters of optimized microemulsion $(n=3)$.

\begin{tabular}{lcccccc}
\hline Formulation & $\mathrm{pH}$ & Globule size $(\mathrm{nm}) \pm$ SEM & PDI \pm SEM & $\begin{array}{c}\text { Zeta potential } \\
(\mathrm{mV}) \pm \text { SEM }\end{array}$ & Viscosity (cp) & Percentage transmittance \\
\hline $\mathrm{R}-1$ & $7.32 \pm 1.12$ & $16.2 \pm 1$ & $0.135 \pm 0.017$ & $-3.02 \pm 0.18$ & $65.38 \pm 0.982$ & 98.2 \\
\hline
\end{tabular}

TABLE 3: Thermodynamic stability studies of selected ranitidine microemulsion.

\begin{tabular}{|c|c|c|c|c|c|c|c|c|c|}
\hline \multirow[b]{2}{*}{ Formulation } & \multirow[b]{2}{*}{ Variables } & \multicolumn{2}{|c|}{ Phase separation } & \multicolumn{2}{|c|}{$\%$ transmittance } & \multicolumn{2}{|c|}{$\% \mathrm{CDR}$} & \multicolumn{2}{|c|}{ Drug precipitation } \\
\hline & & $\begin{array}{l}\text { After } 3 \\
\text { months }\end{array}$ & $\begin{array}{l}\text { After } 6 \\
\text { months }\end{array}$ & $\begin{array}{l}\text { After } 3 \\
\text { months }\end{array}$ & $\begin{array}{l}\text { After } 6 \\
\text { months }\end{array}$ & $\begin{array}{l}\text { After } 3 \\
\text { months }\end{array}$ & $\begin{array}{l}\text { After } 6 \\
\text { months }\end{array}$ & $\begin{array}{l}\text { After } 3 \\
\text { months }\end{array}$ & $\begin{array}{l}\text { After } 6 \\
\text { months }\end{array}$ \\
\hline \multirow{3}{*}{ R-1 } & $2-8^{\circ} \mathrm{C}$ & No & No & 87.4 & 87.2 & $94.40 \pm 1.32$ & $94.37 \pm 1.24$ & Absent & Absent \\
\hline & $25 \pm 2^{\circ} \mathrm{C}$ & No & No & 88.6 & 88.1 & $94.35 \pm 1.45$ & $94.32 \pm 1.62$ & Absent & Absent \\
\hline & $50 \pm 2^{\circ} \mathrm{C}$ & No & No & 88.4 & 88.7 & $94.19 \pm 1.29$ & $94.12 \pm 1.34$ & Absent & Absent \\
\hline
\end{tabular}

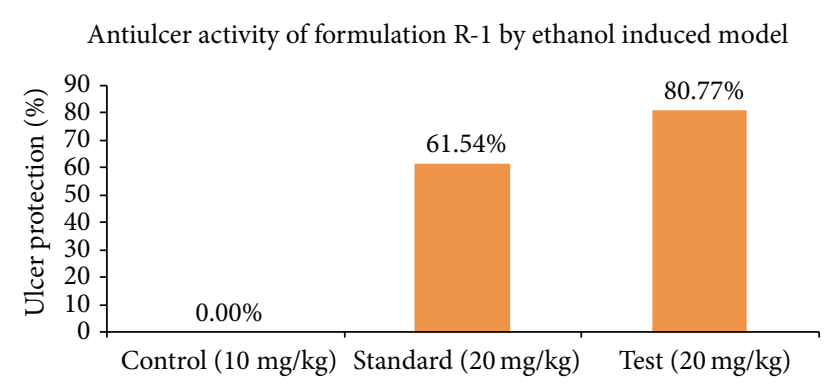

Figure 1: Percentage ulcer protection by standard drug and microemulsion formulation in ethanol-induced gastric ulcer.

TABLE 4: Antiulcer activity of ranitidine formulation on ethanol induced gastric ulcer in rats.

\begin{tabular}{lcccc}
\hline Groups & Induction & Dose $^{\#}$ & $\begin{array}{c}\text { Ulcer } \\
\text { index }\end{array}$ & $\begin{array}{c}\% \\
\text { protection }\end{array}$ \\
\hline Group I & $\begin{array}{c}\text { Normal } \\
\text { saline }\end{array}$ & 10 & $13 \pm 1.0$ & - \\
Group II & Ranitidine & 20 & $5 \pm 0.63$ & $61.54^{* * *}$ \\
Group III & Formulation & 20 & $2.5 \pm 0.92$ & $80.77^{* * *}$ \\
\hline
\end{tabular}

${ }^{\#} \mathrm{~mL} / \mathrm{kg}$ or $\mathrm{mg} / \mathrm{kg}$; values are mean $\pm \mathrm{SEM} ; n=6 ;{ }^{* * *} P<0.05$ versus control.

3.3. Pharmacokinetic Studies. The pharmacokinetic study was performed to quantify ranitidine, after oral administration of test formulation (R-1). The plasma concentrationtime profiles of the drug in male New Zealand albino rabbits following oral administration of the microemulsion formulation and standard drugs were compared.

Figure 3 shows mean plasma concentration-time curve of ranitidine after a single oral administration of standard drug and test formulation. The results of pharmacokinetic study are presented in Tables 5 and 6 . The microemulsion (R-1) demonstrated a longer $T_{\max }(4.5 \mathrm{hr})$ compared with standard drugs $(1.8 \mathrm{hr})$ and sustained the release of drugs over $24 \mathrm{hrs}$ because the drug needs to be released out from the oil phase thereby resulting in a delayed $T_{\max }$ [15]. Ranitidine microemulsion exhibited the higher absorption and $C_{\max }$ achieved from the optimized ranitidine

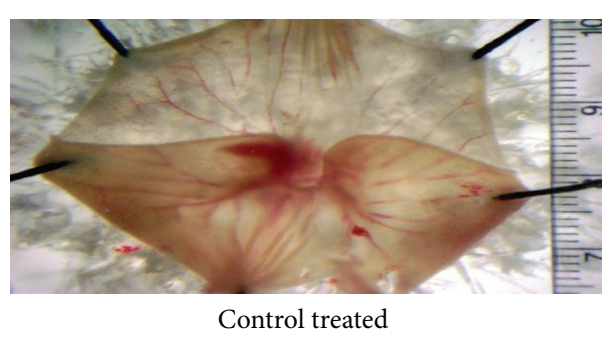

(a)

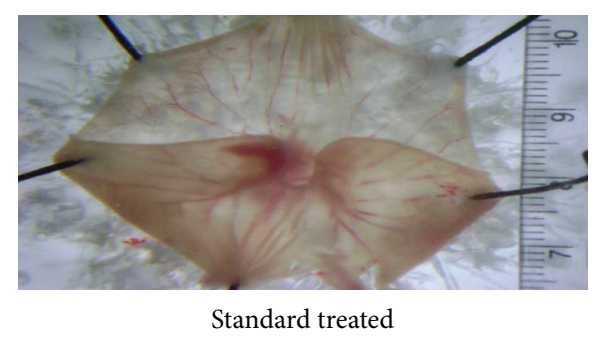

(b)

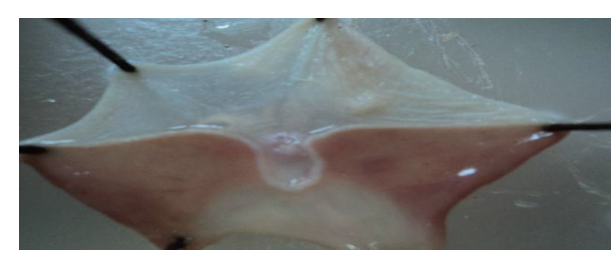

Formulation treated

(c)

FIGURE 2: Photographs of stomach: ethanol-induced gastric ulcers in different groups of treated rats.

formulation $(863.20 \mathrm{ng} \cdot \mathrm{h} / \mathrm{mL})$ was higher than the standard (442.20 ng/mL).

Area under the curve (AUC) for microemulsion showed almost a 1.4-fold increment from AUC generated after administering standard ranitidine solution indicating a significant enhancement of ranitidine's bioavailability when given orally as microemulsions [16]. It was found that $\mathrm{AUC}_{0-24} \mathrm{hr}$ obtained from the optimized ranitidine test formulation (5426.5 $\mathrm{ng} \cdot \mathrm{h} / \mathrm{mL}$ ) was significantly higher than the standard 


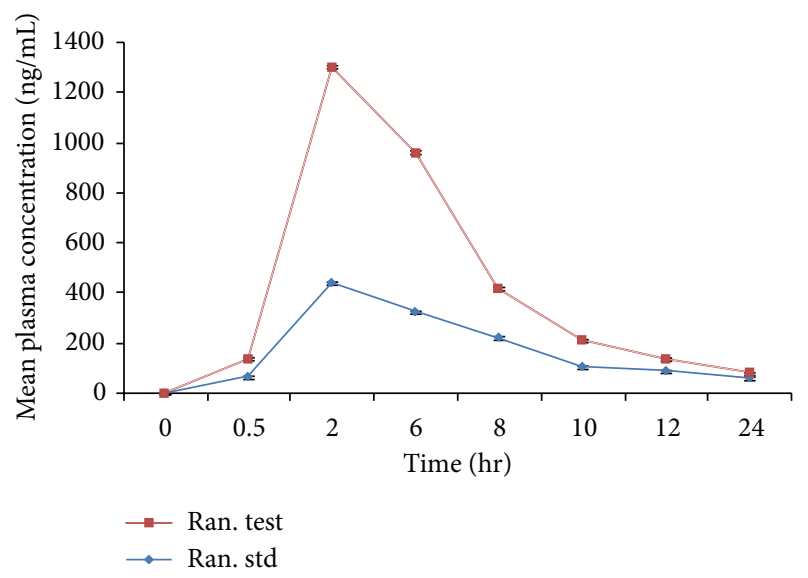

FIGURE 3: Comparison of pharmacokinetic profiles of standard drug and oral microemulsion of ranitidine (R-1).

TABLE 5: Results of pharmacokinetics study on standard ranitidine and test formulation.

\begin{tabular}{lcc}
\hline \multirow{2}{*}{ Time (hr) } & \multicolumn{2}{c}{ Plasma concentration $(\mathrm{ng} / \mathrm{mL})$} \\
& Ranitidine standard & Ranitidine test (R-1) \\
\hline 0.00 & 0.000 & 0.000 \\
0.50 & 66.20 & 74.30 \\
2.00 & 442.20 & 863.20 \\
6.00 & 326.00 & 638.60 \\
8.00 & 223.40 & 196.80 \\
10.00 & 106.40 & 106.20 \\
12.00 & 89.70 & 49.20 \\
24.00 & 62.10 & 18.70 \\
\hline
\end{tabular}

TABLE 6: Pharmacokinetic data of standard ranitidine and test formulation.

\begin{tabular}{lcc}
\hline $\begin{array}{l}\text { Pharmacokinetic } \\
\text { parameters }\end{array}$ & $\begin{array}{c}\text { Ranitidine } \\
\text { standard }\end{array}$ & $\begin{array}{c}\text { Ranitidine test } \\
(\mathrm{R}-1)\end{array}$ \\
\hline $\mathrm{AUC}_{(0-24)}(\mathrm{ng} \cdot \mathrm{h} / \mathrm{mL})$ & 3920.4 & 5426.50 \\
$C_{\max }(\mathrm{ng} / \mathrm{mL})$ & 442.20 & 863.20 \\
$T_{\max }(\mathrm{hr})$ & 1.800 & 4.500 \\
\hline
\end{tabular}

ranitidine (3920.4 $\mathrm{ng} \cdot \mathrm{h} / \mathrm{mL}$ ). The significant differences of the factors leading to drug absorption in vivo between the microemulsion preparation and standard drug were probably attributed to the following.

Ranitidine belongs to BCS class III drug; the oral absorption as well as the bioavailability of the drug is mainly limited due to low intestinal permeability. The surfactant and cosurfactant (Tween-80 and PEG 400) may have contributed to an increase in the permeability of the intestinal membrane or improved the affinity between lipid particles and the intestinal membrane. Further, due to small particle size, microemulsions may adhere to the gut membrane or enter the intervillar spaces thus extending gastrointestinal residence time in the gastrointestinal tract [17]. Moreover, microsized preparation ensures greater surface area and also the presence of Tween-80 as a surfactant in the microemulsion formulation might modulate the intestinal membrane permeability through apically polarized efflux system leading to enhanced oral bioavailability [18].

\section{Conclusion}

In the present investigation, the utility of microemulsion as carrier for oral delivery of ranitidine was studied. The pharmacodynamic study (ethanol-induced ulcer model) revealed that ranitidine microemulsion showed lower incidence of mucosal damage when compared with standard drug, both administered orally, indicating the superiority of oral ranitidine microemulsion over standard ranitidine. The pharmacokinetic studies reveal that the oral administration of ranitidine microemulsion sustained the release of drugs over $24 \mathrm{hrs}$. As a consequence of this, decrease in the dose and frequency of administration for drugs is possible to achieve the desired therapeutic activity.

\section{Conflict of Interests}

The authors declare that there is no conflict of interests regarding the publication of this paper.

\section{Acknowledgments}

The authors are grateful to SMS Pharmaceuticals Pvt. Ltd., Hyderabad, India, for their kind gift samples of the drug, ranitidine hydrochloride. The authors are thankful to Pinnacle Biomedical Research institute (PBRI), Bhopal, India, for their assistance in animal studies. They are also grateful to Nishka Scientific \& Reference Laboratories, Hyderabad, India, for their kind help in pharmacokinetic studies.

\section{References}

[1] S. Karthikeyan and K. Gobianand, "Antiulcer activity of ethanol leaf extract of Cassia fistula," Pharmaceutical Biology, vol. 48, no. 8, pp. 869-877, 2010.

[2] S. Ramchandran, G. Poovi, and M. D. Dhanaraju, "Evaluation of gastric and duodenal antiulcer activity of famotidine formulation in experimental animals," Journal of Pharmacological and Toxicological, vol. 6, no. 2, pp. 189-195, 2011.

[3] C. Zhang, L. Wang, X. Guan et al., "Rapid determination of ranitidine in human plasma by liquid chromatography-tandem mass spectrometry and its application to a clinical pharmacokinetic study," Chemical Research in Chinese Universities, vol. 26, no. 6, pp. 910-914, 2010.

[4] D. Hollander, A. Tarnawski, W. J. Krause, and H. Gergely, "Protective effect of sucralfate against alcohol-induced gastric mucosal injury in the rat: macroscopic, histologic, ultrastructural , and functional time sequence analysis," Gastroenterology, vol. 88, no. 1, pp. 366-374, 1985.

[5] S. G. Patel, S. J. Rajput, A. Groshev, and V. B. Sutariya, "Preparation and characterization of microemulsion of cilostazol for enhancement of oral bioavailability," Current Drug Delivery, vol. 11, no. 3, pp. 531-540, 2014. 
[6] Q. Cai, H. Sun, Y. Pen et al., "A potent and orally active antagonist of multiple inhibitor of apoptosis proteins (IAPs) (SM406/AT-406) in clinical development for cancer treatment," Journal of Medicinal Chemistry, vol. 54, no. 8, pp. 2714-2726, 2011.

[7] R. ParveenShaika, S. B. Puttagunta, C. B. Kothapalli, B. Z. S. Awen, and B. R. Challa, "A validated LC-MS/MS method for the determination of tolterodine and its metabolite in rat plasma and application to pharmacokinetic study," Journal of Pharmaceutical Analysis, vol. 3, no. 6, pp. 489-499, 2013.

[8] R. G. Thorne and W. H. Frey II, "Delivery of neurotrophic factors to the central nervous system: pharmacokinetic considerations," Clinical Pharmacokinetics, vol. 40, no. 12, pp. 907-946, 2001.

[9] J. Born, T. Lange, and W. Kern, "Sniffing neuropeptides: a transnasal approach to the human brain," Nature Neuroscience, vol. 5, pp. 514-516, 2002.

[10] L. Illum, "Nasal drug delivery: new developments and strategies," Drug Discovery Today, vol. 7, no. 23, pp. 1184-1189, 2002.

[11] M. R. Patel, R. B. Patel, J. R. Parikh, A. B. Solanki, and B. G. Patel, "Effect of formulation components on the in vitro permeation of microemulsion drug delivery system of fluconazole," AAPS PharmSciTech, vol. 10, no. 3, pp. 917-923, 2009.

[12] M. R. Patel, R. B. Patel, and J. R. Parikh, "Investigation of efficiency of isopropyl myristate-based oil in water microemulsions for topical delivery of fluconazole," International Journal of Biomedical and Pharmaceutical Sciences, vol. 3, pp. 60-68, 2009.

[13] M. R. Patel, R. B. Patel, J. R. Parikh, A. B. Solanki, and B. G. Patel, "Investigating effect of microemulsion components: In vitro permeation of ketoconazole," Pharmaceutical Development and Technology, vol. 16, no. 3, pp. 250-258, 2011.

[14] G. Sener, K. Paskaloglu, and G. Ayanoglu-Dülger, "Protective effect of increasing doses of famotidine, omeprazole, lansoprazole, and melatonin against ethanol-induced gastric damage in rats," Indian Journal of Pharmacology, vol. 36, no. 3, pp. 171-174, 2004.

[15] Y.-M. Yin, F.-D. Cui, C.-F. Mu et al., "Docetaxel microemulsion for enhanced oral bioavailability: preparation and in vitro and in vivo evaluation," Journal of Controlled Release, vol. 140, no. 2, pp. 86-94, 2009.

[16] G. Sharma, K. Wilson, C. F. van der Walle, N. Sattar, J. R. Petrie, and M. N. V. Ravi Kumar, "Microemulsions for oral delivery of insulin: design, development and evaluation in streptozotocin induced diabetic rats," European Journal of Pharmaceutics and Biopharmaceutics, vol. 76, no. 2, pp. 159-169, 2010.

[17] L. Hu, H. Wu, F. Niu, C. Yan, X. Yang, and Y. Jia, "Design of fenofibrate microemulsion for improved bioavailability," International Journal of Pharmaceutics, vol. 420, no. 2, pp. 251255, 2011.

[18] H. Araya, M. Tomita, and M. Hayashi, "The novel formulation design of $\mathrm{O} / \mathrm{W}$ microemulsion for improving the gastrointestinal absorption of poorly water soluble compounds," International Journal of Pharmaceutics, vol. 305, no. 1-2, pp. 61-74, 2005. 

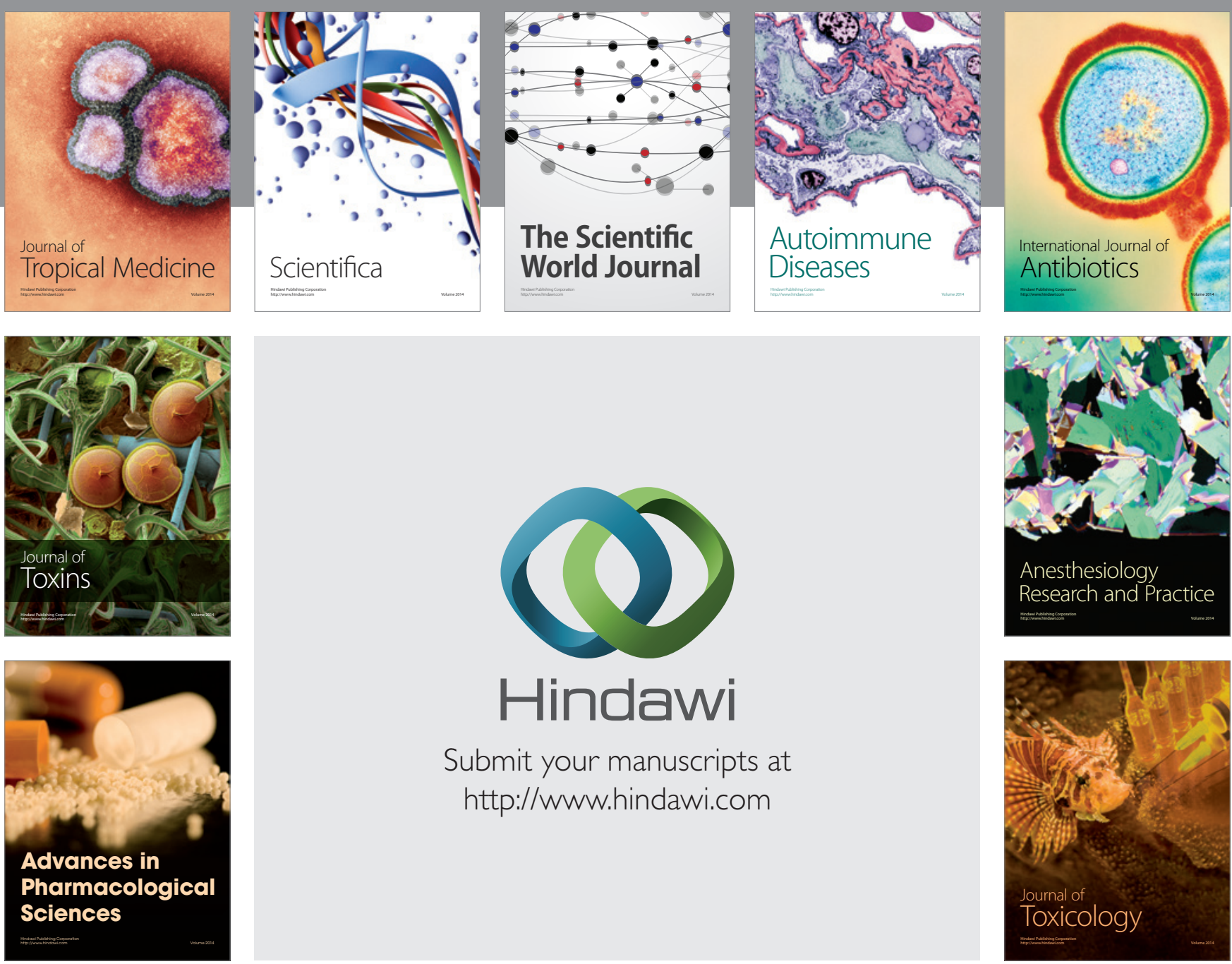

\section{Hindawi}

Submit your manuscripts at

http://www.hindawi.com
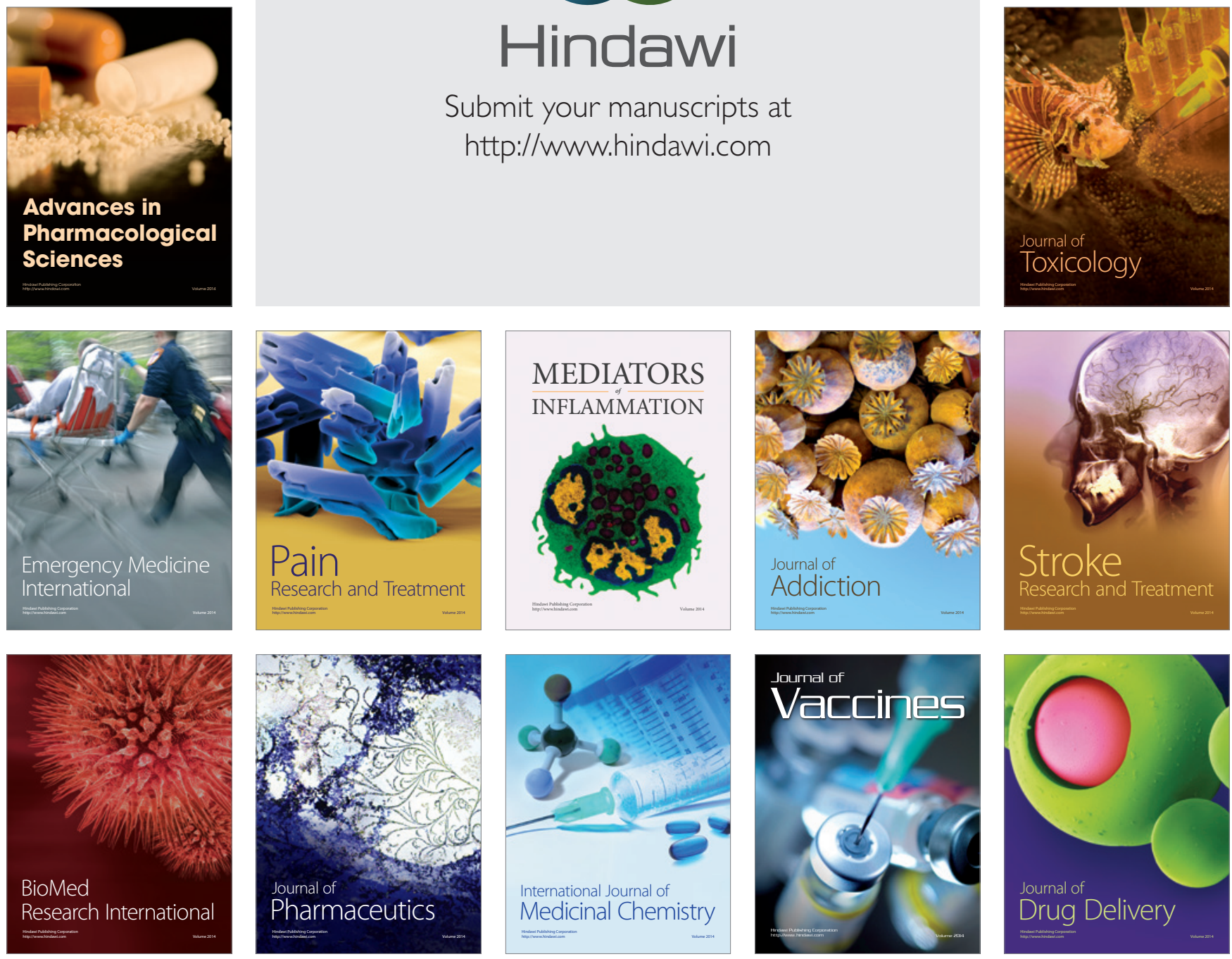